\title{
Prevalence and genotype distribution of genital human papillomavirus infection in female sex workers in the world: a systematic review and meta-analysis
}

Mohammad Farahmand ${ }^{1}$, Mohsen Moghoofei ${ }^{2}$, Abolfazl Dorost ${ }^{3}$, Saeedeh Abbasi ${ }^{4}$, Seyed Hamidreza Monavari ${ }^{4}$, Seyed Jalal Kiani ${ }^{4}$ and Ahmad Tavakoli ${ }^{4,5^{*}}$ (i)

\begin{abstract}
Background: Female sex workers (FSWs) are amongst the most susceptible groups to acquire human papillomavirus (HPV) infection and consequently, to develop cervical intraepithelial neoplasia and cervical cancer. This is the first systematic review and meta-analysis to provide estimates of the pooled prevalence of HPV infection and the distribution of HPV types among FSWs across the world.

Methods: Five computerized databases were searched for relevant studies published since the inception date of databases to September 2019. The pooled HPV prevalence was calculated by the random effect model described by DerSimonian-Laird. Subgroup analysis was performed to identify the probable sources of heterogeneity. The meta-analysis was performed using the "Metaprop" function in the R package Meta.

Results: Sixty-two studies involving 21,402 FSWs from 33 countries were included in this meta-analysis, and the pooled HPV prevalence was 42.6\% (95\% confidence interval (Cl): 38.5-46.7\%). HPV-16 (10.1, 95\% Cl: 8.2-12.5\%), HPV52 (7.9, 95\% Cl: 5.9-10.7\%), and HPV-53 (6.0, 95\% Cl: 4.4-8.1\%) were the most common high-risk HPV types identified among FSWs. The pooled estimated prevalence of HPV infection among FSWs before and after 2010 were slightly different, $43.6 \%$ (95\% Cl: $36.1-51.4 \%)$ and $41.9 \%$ (95\% Cl: 37.2-46.8\%), respectively.

Conclusion: Due to the high prevalence of HPV infection, particularly with high-risk types, FSWs have a great susceptibility to the development of cervical and vaginal cancers. Furthermore, they can transmit their infection to their clients, which may result in a high prevalence of HPV and the incidence of HPV-associated malignancies among the general population.
\end{abstract}

Keywords: Human papillomavirus, HPV, Female sex workers, Prostitution, Epidemiology, Meta-analysis

\footnotetext{
* Correspondence: Tavakoli.a@iums.ac.ir

${ }^{4}$ Department of Medical Virology, Faculty of Medicine, Iran University of Medical Sciences, Tehran, Iran

${ }^{5}$ Research Center of Pediatric Infectious Diseases, Institute of Immunology and Infectious Diseases, Iran University of Medical Sciences, Tehran, Iran

Full list of author information is available at the end of the article
}

(c) The Author(s). 2020 Open Access This article is licensed under a Creative Commons Attribution 4.0 International License, which permits use, sharing, adaptation, distribution and reproduction in any medium or format, as long as you give appropriate credit to the original author(s) and the source, provide a link to the Creative Commons licence, and indicate if changes were made. The images or other third party material in this article are included in the article's Creative Commons licence, unless indicated otherwise in a credit line to the material. If material is not included in the article's Creative Commons licence and your intended use is not permitted by statutory regulation or exceeds the permitted use, you will need to obtain permission directly from the copyright holder. To view a copy of this licence, visit http://creativecommons.org/licenses/by/4.0/ The Creative Commons Public Domain Dedication waiver (http://creativecommons.org/publicdomain/zero/1.0/) applies to the data made available in this article, unless otherwise stated in a credit line to the data. 


\section{Background}

Human papillomavirus (HPV) is the most frequently sexually transmitted pathogen in humans. There are more than 200 different HPV genotypes recognized to date which are classified into two major groups, highrisk and low-risk genotypes in terms of their malignancy-causing potential $[1,2]$. HPV types 6 and 11 are known to be responsible for $90 \%$ of genital warts, and types 16 and 18 together cause up to $70 \%$ of invasive cervical cancer worldwide. Along with cervical cancer, HPV types 16 and 18 are responsible for $40-50 \%$ of invasive vulvar cancer and $70 \%$ of vaginal cancer [3]. HPV-16, 18, 31, 33, 35, 39, 45, 51, 52, 56, $58,59,66,68,73$ and 82 are considered high risk genotypes, whereas low-risk genotypes include HPV-6, $11,34,40,42,43,44,54,61,70,72,81$, and 89 [4]. There are three available HPV vaccines licensed by the U.S. Food and Drug Administration (FDA): quadrivalent HPV vaccine, including HPV types 6, 11, 16 , and 18 (Gardasil ${ }^{\circ}$, produced by Merck); bivalent HPV vaccine, including HPV types 16 and 18 (Cervarix $^{\mathrm{Tm}}$, produced by GlaxoSmithKline), and ninevalent vaccine, including HPV types 6, 11, 16, 18, 31, 33, 45, 52 and 58 (Gardasil 9; produced by Merck) [5, 6]. Previous reports suggested that $65-100 \%$ of the sexually active population are exposed to HPV during their lifespan [7]. Men who have sex with men (MSM) as a sexually active group have a high prevalence of HPV infection (81 and 47\% among HIVpositive and HIV-negative MSM, respectively) [8]. The HPV prevalence among women from the general population seems to be lower so that Sabeena et al. have reported the pooled HPV prevalence of $11 \%$ among women attending cervical cancer screening clinics [9].

Cervical cancer is the fourth most frequent type of gynecological cancer worldwide, with a high mortality rate. More than 270,000 women annually die from cervical cancer worldwide, which most of them ( $85 \%)$ are in developing countries [10, 11]. Almost all cases of cervical cancer are caused by persistent HPV infection, which is usually transmitted by sexual intercourse. Accordingly, cervical cancer is more common among females with multiple sex partners [12]. In a study conducted by Liu et al., the association between the number of sexual partners and the risk of cervical cancer was assessed through a meta-analysis [13]. Their results suggested that the number of sexual partners was related to the development of cervical cancer.

Female sex workers (FSWs) are a group of females who provide sexual services for economic remuneration [14]. They are a heterogeneous population group who work in varied work environments and community organizations. Street-based sex workers are mainly illegal workers who solicit clients on the street or in public settings such as markets, parks, cinema halls, and service them in alleys, or the clients' cars. Another group is indoor-based sex workers who are employed to work in brothels, hotels, massage parlors, saunas, and lodges. In some cases, they might solicit clients independently based on both on-street and off-street, by online advertising in newspapers or by phone or text, or might work for a pimp or manager [15-17]. FSWs are at greatly elevated risk of acquiring sexually transmitted infections (STIs), including HPV, and their clients can act as a bridging population toward the general population. The major underlying risk factors for this high-risk group include multiple sex partners $[14,18]$, unsafe sex behaviors $[19,20]$, earlier age of sex work debut [21, 22], the years of engaging in sex work [23], and low educational status [24]. It is believed that sexual contact with FSWs contributes to HPV transmission and leads to a high prevalence of cervical cancer in this population [24]. Besides, they elevate the risk of penile cancer in males by the spread of the virus to their male clients [24, 25]. Previous studies have been reported that FSWs have more than two times the probability of having HPV infection compared with women from the general population and have an increased prevalence of abnormal pap smears [26, 27]. It has been reported that FSWs have significantly more cytological abnormalities such as atypical squamous cells of undetermined significance (ASCUS) than women from the normal population. Following abnormal cytology and HPV infection, the occurrence of cervical intraepithelial neoplasia (CIN) 1, CIN 2, or CIN 3 was significantly higher among FSWs compared to the general population [28]. Thus, FSWs are thought to be at elevated risk of cervical dysplasia development due to the high HPV exposure [24, 28, 29].

There are a few review publications focused on the prevalence of HPV infection in the FSW population worldwide. Soohoo et al. reviewed articles assessing the prevalence of HPV types among FSWs in the world [30]. Based on 35 peer-reviewed publications included in their review, the median overall HPV prevalence was $42.7 \%$, with a range of 2.3 to $100 \%$. The ten most common HPV types were HPV-6 (11.5\%), 16 (38.9\%), 18 (23.1\%), 31 (28.4\%), 33 (25.0\%), 39 (21.6\%), 51 (25.0\%), 52 (32.7\%), 56 (24.0\%) and $58(26.0 \%)$. In another study conducted by Peng et al. in 2010, a meta-analytic approach was used to estimate the prevalence and genotype distribution of cervical HPV infection among FSWs in Asia [31]. They found that crude estimates of the cervical 
prevalence of HPV among 4198 Asian FSWs ranged from 12.8 to $84.8 \%$. According to their results, HPV prevalence among FSWs was nearly 10 times higher than that of the general population of women.

Regarding the important role of HPV infection in the development of cervical cancer and other associated diseases, numerous studies have investigated the prevalence and the distribution of HPV types within FSWs. However, there is not a systematic review and meta-analysis to estimate the overall pooled prevalence of HPV infection in this high-risk population. To the best of our knowledge, this is the first systematic review and meta-analysis that characterizes the global epidemiology of HPV infection and the distribution of high-risk and low-risk HPV types among FSWs. Our study will provide a comprehensive picture of the health status of women engaged in sex trading in the aspect of HPV infection, as one of the major sexually transmitted diseases. The high prevalence of HPV infection among FSWs will persuade policy-makers to promote strategies such as cervical screening and HPV vaccination to reduce the incidence of cervical cancer in this population.

\section{Methods}

This systematic review and meta-analysis was based on the items outlined in the Preferred Reporting Items for Systematic Reviews and Meta-Analyses (PRISMA) guideline [32].

\section{Search strategy}

We conducted an electronic literature search using Web of Science, Scopus, PubMed, Embase, and Google scholar from database inception to September 2019 to identify eligible publications. The details of the search terms for each database are presented in Additional file 1. Moreover, reference lists of all articles included were scanned by hand to find additional eligible studies. All identified records were imported to EndNote software version X8 (Thomson Reuters, California, USA) for further management.

\section{Selection criteria}

In our study, FSWs are defined as women who offer sexual services in return for money, goods, or other markers of economic remuneration. Studies were considered eligible for inclusion if they reported: (1) original data about the prevalence measure for HPV infection among FSWs published in the English language in peer-reviewed journals; (2) the prevalence of HPV DNA in different genital specimens, including cervical, endocervical, vaginal, and cervico-vaginal samples; (3) Studies detecting HPV DNA and transcripts with polymerase chain reaction (PCR),
Hybridization, PCR-Hybridization, and Transcriptionmediated amplification (TMA) methods; (4) letters to the editor, short communications, and English abstracts with sufficient data. Studies meeting any of the following criteria were excluded: (1) studies estimating the incidence of HPV infection among FSWs; (2) studies of the incidence and the prevalence of HPV infection among transgenders, male sex workers, gays, lesbians, and clients of FSWs; (3) Serological studies that measured antibodies to HPV using methods such as enzyme-linked immunosorbent assay (ELISA); (4) review articles, case reports, posters, and conference abstracts; (5) articles in languages other than English with non-English abstracts.

\section{Data extraction and quality assessment}

Two investigators independently reviewed the eligible articles and extracted data, including the first author's last name, publication year, study location, total sample size, type of specimen, diagnostic methods, diagnostic indexes, number of HPV-positive cases, and types of HPV. The extracted data were imported into an Excel spreadsheet (Microsoft Corporation, Redmond, WA, USA), and any discrepancies were resolved by a third investigator. A quality assessment of the retrieved studies was performed according to a modified checklist based on the guidelines of the strengthening the reporting of observational studies in epidemiology (STROBE) [33, 34]. The checklist was comprised of 12 questions covering different methodological perspectives. Studies were deemed eligible for the main meta-analysis if they achieved a validity score of at least 8 out of a maximum of 12 .

\section{Statistical analysis}

To measure the pooled prevalence of HPV infection among FSWs, a DerSimonian-Laird random-effects meta-analysis was performed [35]. The method is based on the inverse-variance approach, making an adjustment to the study weights dependent on the amount of variation, or heterogeneity, among the different intervention effects. The results of the random-effects and the fixed-effect methods will be identical when there is no heterogeneity between the studies. Where heterogeneity is present, confidence intervals (CIs) around the random-effects summary estimates are wider than CIs around the fixed-effect summary estimates and corresponding claims of statistical significance will be more conservative [36].

To stabilize the variance and normalize their distribution, the logit transformation was used, and the Clopper-Pearson method was applied to estimate the 95\% exact CIs for proportions [37]. To explore the possible sources of heterogeneity, subgroup analyses were 
performed based on study location, type of specimen, diagnostic method, and diagnostic index. To assess the heterogeneity across the included studies, the $\mathrm{I}^{2}$ statistic was employed, in which the result is expressed as a percentage [38]. Jackson's method was used for the estimation of the confidence interval of $\operatorname{tau}^{\wedge} 2$ and tau [39]. The meta-analysis was performed using the "Metaprop" function in the $R$ package "meta" [40] (version 3.5.3 [2019-03-11], R Foundation for Statistical Computing, Vienna, Austria). For all statistical tests, differences with $P$ values of $<0.05$ were considered statistically significant. Graph of the prevalence and genotype distribution of genital HPV was drawn using GraphPad Prism 7.1 for Windows (GraphPad Software, La Jolla California USA).

\section{Results}

\section{Literature search}

In the initial literature review, 810 articles were identified through searching the five electronic international databases. Also, 4 relevant articles were found and included by a manual search of the reference lists of the identified articles. A total of $402 \mathrm{du}-$ plicates was excluded, and then 412 articles were reviewed by title and abstract, which led to the elimination of 269 articles. The remaining 143 articles were checked for eligibility by the full-text review. After the full-text screening, 77 articles were excluded based on the inclusion/exclusion criteria. Based on the modified STROBE checklist, 62 papers were considered to have good quality (obtained scores of 8 and above), and 4 papers were failed to reach score 8 . Overall, 62 articles were included in this systematic review and meta-analysis. Figure 1 shows the process of literature retrieval and screening using a flow diagram.

\section{Study characteristics}

The characteristics of eligible studies in this systematic review and meta-analysis are summarized in Table 1. Sixty-two studies with a total of 21,402 FSWs were included in this meta-analysis. The studies' publication dates ranged from 1992 to 2019, and they examined the population of 33 countries. The largest study included 2308 and the smallest included 34 FSWs. Most studies investigating the prevalence of HPV infection were from Kenya $(n=7)$ and China $(n=4)$. Out of 62 included studies, 35 assessed the genotype distribution of HPV among FSWs. In one study [57], researchers were investigated the prevalence of only one type of HPV (HPV-16) among FSWs. Therefore, we excluded this study from the main meta-analysis calculating the pooled prevalence to avoid underestimating, and the results of genotype distribution were just included for the analysis. In total, $39.3 \%$ of the studies $(n=24)$ were performed before 2010 , and $60.7 \%$ of the studies $(n=37)$ were performed after 2010.

\section{Prevalence of genital HPV infection among FSWs}

Our current study aimed to determine the pooled prevalence of HPV infection in 21,179 FSWs from 32 countries, and the range was from 5.5 to $84.7 \%$ of the selected individual studies. Figure 2 shows the prevalence of HPV and 95\% CI estimates from individual studies according to the random-effects model. The pooled prevalence of HPV infection among FSWs was 42.6\% (95\% CI: $38.5-46.7 \%$ ).

We divided the individual studies into two time periods of publication, before and after 2010. The polled estimated prevalence of HPV infection among FSWs before and after 2010 were slightly different, 43.6\% (95\% CI: $36.1-51.4 \%$ ) and $41.9 \%$ (95\% CI: $37.2-46.8 \%$ ), respectively (Fig. 2). However, the difference was not statistically significant $(P=0.71)$. Among studies performed after 2010, the maximum and minimum prevalence of HPV infection among FSWs were found in Hungary and Mexico, respectively $(82.3$, 95\%CI: $65.9-91.8 \%$ vs 5.5 , 95\%CI: $3.5-8.7 \%)$. The most frequent HPV types detected in Mexico were HPV-73 (5.8, 95\%CI: 4.1-8.3\%), HPV-39 (5.6, 95\%CI: 3.9-8.0\%), and HPV-54 (5.2, 95\% CI: $3.6-7.6 \%$ ), while the only one study performed in Hungary [60] did not perform any analysis for HPV typing.

For studies with HPV DNA detection in genital samples of FSWs, there was statistically significant difference between the prevalence of HPV using vaginal $(68.4,95 \%$ CI: 37.7-88.5\%), cervical (41.9, 95\% CI: 37.6-46.4\%), cervico-vaginal (46.2, 95\% CI: 40.2-52.2\%), and endocervical (31.1, 95\% CI: $21.1-43.4 \%)$ specimens $(P=0.04)$. Concerning HPV detection methods in genital samples of FSWs, PCR, hybridization, PCR-hybridization, and TMA (transcription-mediated amplification) methods were used. The prevalence of HPV was $43.2 \%$ (95\% CI: $37.8-48.8 \%$ ), $41.4 \%$ (95\% CI: 32.4-51.1\%), 40.9\% (95\% CI: $37.7-44.2 \%$ ), and $31.8 \%$ (95\% CI: $26.6-37.6 \%$ ) when PCR-, hybridization-, PCR-hybridization-, and TMAbased methods were used, respectively, and the difference was statistically significant $(P=0.02)$. Table 2 presents more detailed information on the prevalence of HPV infection among FSWs for subgroups. The geographical distribution of HPV infection among FSWs is shown in global maps in Fig. 3.

\section{Genotype distribution of genital HPV infection in FSWs}

Overall, fifty-two HPV types were detected among FSWs across studies. The five most common highrisk HPV types identified were HPV-16 (10.1, 95\% CI: 


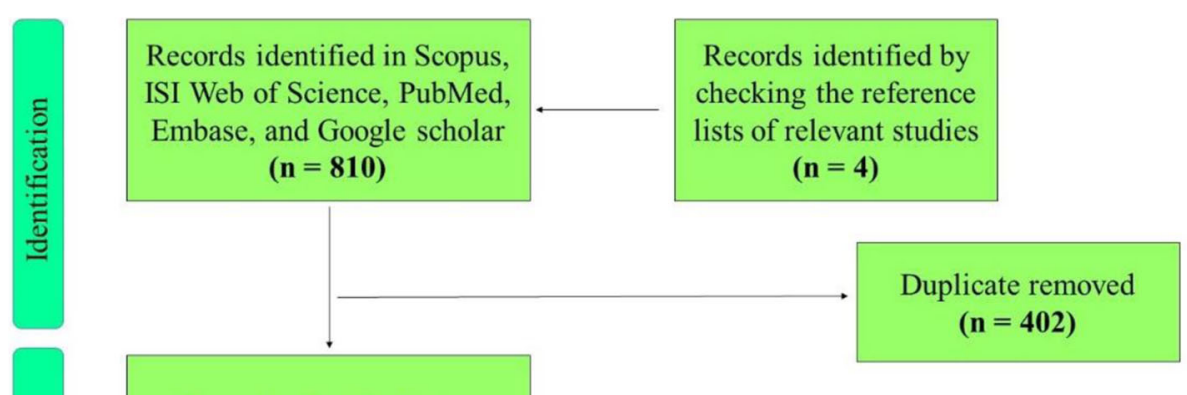

Records after duplicates removed $(n=412)$
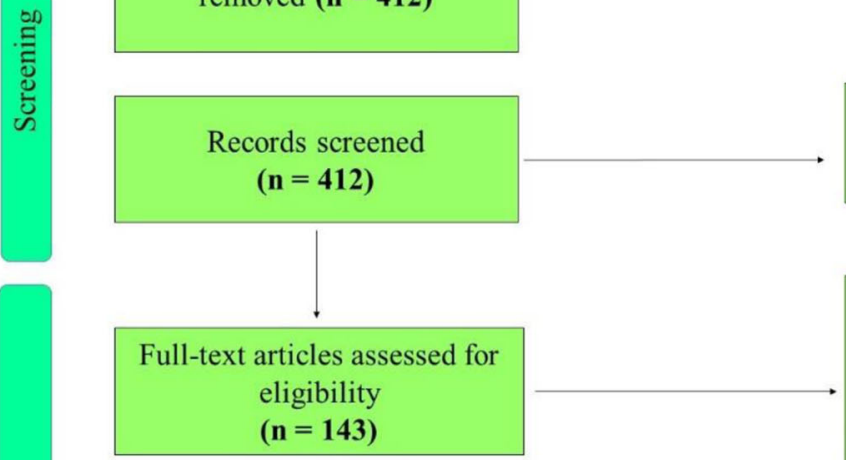

Articles removed by title/abstract

( $\mathrm{n}=\mathbf{2 6 9})$

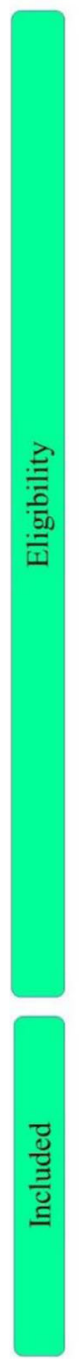

Articles removed after full-text review $(\mathbf{n}=77)$

37 articles were not relevant to the subject; $\mathbf{5}$ articles presented duplicated data;

5 articles had no full text available; 4 articles determined the prevalence of HPV infection in transgenders and transsexuals; 4 articles determined the prevalence of HPV infection in men who have sex with men; $\mathbf{3}$ articles in languages other than English with non-English abstracts;

$\mathbf{3}$ articles determined the incidence of HPV infection;

3 review articles;

2 articles determined the prevalence of HPV infection in male sex workers;

2 articles determined the prevalence of HPV infection in lesbians;

$\mathbf{2}$ articles determined the prevalence of oral

HPV infection in female sex workers;

$\mathbf{2}$ articles determined the risk factors of HPV infection;

2 conference abstracts;

$\mathbf{1}$ article did not specify diagnostic marker

and diagnostic method of HPV;

$\mathbf{1}$ article determined the prevalence of HPV

infection in female sex workers using serum

samples;

1 article determined the prevalence of HPV

infection in clients of female sex workers

Articles removed by

quality assessment $(n=4)$

Fig. 1 Flowchart presenting the steps of literature search and selection 
Table 1 The characteristics of all eligible studies in this systematic review and meta-analysis

\begin{tabular}{|c|c|c|c|c|}
\hline Author [Ref.] & Publication Year & Study location & Total sample size & No. HPV positive \\
\hline Velazquez-Hernandez [41] & 2019 & Mexico & 217 & 12 \\
\hline Diop-Ndiaye [42] & 2019 & Senegal & 436 & 348 \\
\hline Ferre [43] & 2019 & Togo & 310 & 140 \\
\hline Lockhart [44] & 2019 & Kenya & 344 & 97 \\
\hline Adams [14] & 2019 & Ghana & 100 & 26 \\
\hline Shahesmaeili [45] & 2018 & Iran & 1318 & 552 \\
\hline Muñoz-Ramírez [46] & 2018 & Mexico & 105 & 6 \\
\hline Hooi [29] & 2018 & Curaçao & 76 & 19 \\
\hline Richards [47] & 2018 & Dominican Republic & 143 & 62 \\
\hline Bui [48] & 2018 & Cambodia & 200 & 94 \\
\hline Cameron [49] & 2018 & Kenya & 330 & 97 \\
\hline Nasirian [50] & 2017 & Iran & 99 & 7 \\
\hline Marra [51] & 2017 & Netherlands & 304 & 238 \\
\hline Vorsters [52] & 2016 & Belgium & 1334 & 556 \\
\hline Menon [53] & 2016 & Kenya & 616 & 357 \\
\hline Singh [54] & 2016 & India & 120 & 33 \\
\hline Leaungwutiwong [55] & 2015 & Thailand & 100 & 13 \\
\hline Jia [28] & 2015 & China & 309 & 191 \\
\hline Gomih-Alakija [56] & 2014 & Kenya & 349 & 103 \\
\hline Aho [57] & 2014 & Guinea & 223 & 27 \\
\hline Wang [58] & 2013 & China & 288 & 192 \\
\hline Patel [59] & 2013 & Kenya & 296 & 195 \\
\hline Marek [60] & 2013 & Hungary & 34 & 28 \\
\hline Hoang [61] & 2013 & Vietnam & 281 & 139 \\
\hline Ersan [24] & 2013 & Turkey & 239 & 48 \\
\hline Yin [62] & 2013 & China & 802 & 309 \\
\hline Keten [63] & 2013 & Turkey & 137 & 53 \\
\hline Li [64] & 2012 & China & 810 & 315 \\
\hline Ghosh [65] & 2012 & India & 45 & 35 \\
\hline Couture [66] & 2012 & Cambodia & 220 & 90 \\
\hline Brown [67] & 2012 & Peru & 199 & 133 \\
\hline Shikova [68] & 2011 & Bulgaria & 106 & 46 \\
\hline Matsushita [69] & 2011 & Japan & 196 & 103 \\
\hline Dal Pogetto [70] & 2011 & Brazil & 102 & 46 \\
\hline Znazen [71] & 2010 & Tunisia & 188 & 83 \\
\hline Smith [72] & 2010 & Madagascar & 90 & 33 \\
\hline Luchters [73] & 2010 & Kenya & 776 & 429 \\
\hline Rhee [74] & 2010 & South Korea & 2308 & 939 \\
\hline Valle's [26] & 2009 & Guatemala & 297 & 200 \\
\hline Miyashita [75] & 2009 & Philippines & 369 & 211 \\
\hline del Amo [76] & 2009 & Spain & 549 & 169 \\
\hline Sultana [77] & 2008 & Bangladesh & 293 & 222 \\
\hline Sarkar [78] & 2008 & India & 229 & 58 \\
\hline Hernandez [79] & 2008 & Vietnam & 282 & 239 \\
\hline
\end{tabular}


Table 1 The characteristics of all eligible studies in this systematic review and meta-analysis (Continued)

\begin{tabular}{lllll}
\hline Author [Ref.] & Publication Year & Study location & Total sample size & No. HPV positive \\
\hline Yun [80] & 2008 & South Korea & 188 & 157 \\
Gazi [81] & 2008 & Turkey & 124 & 12 \\
Didelot-Rousseau [82] & 2006 & Burkina Faso & 360 & 238 \\
Chandeying [83] & 2006 & Thailand & 524 & 120 \\
De Marco [84] & 2006 & Tunisia & 64 & 28 \\
del Amo [85] & 2005 & Spain & 734 & 52 \\
Canadas [86] & 2004 & Spain & 187 & 19 \\
Baay [87] & 2004 & Belgium & 61 & 72 \\
Mak [88] & Belgium & 99 & 91 \\
Tideman [89] & Australia & 288 & 194 \\
Choi [90] & South Korea & 417 & 242 \\
Juarez-Figueroa [91] & 2003 & Mexico & 495 & 27 \\
Chan [92] & 2003 & Singapore & 187 & 59 \\
Kjaer [93] & 2001 & Denmark & 182 & 307 \\
Ishi [94] & 2001 & Japan & 546 & 293 \\
Langley [95] & 2000 & Senegal & 681 & \\
Van Doornum [96] & 2000 & Netherlands & 121 & \\
Kreiss [97] & 1996 & Kenya & 198 & \\
\hline
\end{tabular}

NR Not reported

8.2-12.5\%), HPV-52 (7.9, 95\% CI: 5.9-10.7\%), HPV-53 (6.0, 95\% CI: 4.4-8.1\%), HPV-18 (5.4, 95\% CI: $4.4-$ 6.8\%) and HPV-58 (5.6, 95\% CI: 4.2-7.3\%). HPV-89 (7.0, 95\% CI: $4.2-11.5 \%)$, HPV-50 (4.1, 95\% CI: $2.2-$ 7.6\%), HPV-6 (3.6, 95\% CI: 2.8-4.6\%), HPV-54 (3.4, 95\% CI: $2.5-4.5 \%)$, and HPV-71 (3.3, 95\% CI: $1.9-$ $5.8 \%$ ) were also the most common low-risk HPV types identified among FSWs (Fig. 4).

\section{Discussion}

Sexual intercourse is the main route of transmission of HPV infection, which is known as one of the most common infections around the world. According to this view, FSWs are amongst the most vulnerable group to acquire HPV infection and consequently, to develop precursors of cervical cancer. In part, this arises from the fact that they are constantly being exposed to a large number of risk factors facilitating the spread of sexually transmitted diseases [30]. Previous studies among the general population have reported that the prevalence of HPV ranged from 9 to $13 \%$ in the world [98]. As expected, our findings indicated that the number of HPV-positive cases is significantly higher among FSWs compared to the general population, and the prevalence varied from 13 to $82 \%$ across the world.

Concerning the overall prevalence and genotype distribution of cervical HPV infection among FSWs, to date, only one meta-analysis has been published by
Peng et al. in 2012, which was conducted on 4198 FSWs from nine Asian countries [31]. Their study found a high HPV prevalence in different regions of Asia, so that the overall HPV prevalence in East, South-east, and South Asia were 49.6, 42.9, and $29.3 \%$, respectively. Consistent with this, the results of our meta-analysis also indicated that FSWs in most Asian countries, like Bangladesh, China, Cambodia, India, Japan, Philippines, South Korea, and Vietnam had a prevalence of HPV infection greater than $40 \%$.

The wide range of variations between the different studies can be attributed to differences in the sociodemographic and behavioral characteristics of FSWs. As an example, we found that Mexican FSWs exhibit low levels of HPV infection. It may be related to the implementation of preventive programs such as primary cervical cancer screening, condom promotion, and HPV vaccination, which were effective to reduce the prevalence of HPV infection [41]. The application of vaccines against HPV infection in 11-year-old girls is a part of Mexico's national immunization program [46]. Previous studies showed that registered FSWs are more likely to engage in screening and prevention programs and more likely to use condoms than clandestine FSWs [99, 100]. Regarding the sex work environment, previous reports indicated that streetbased FSWs are at a higher risk for STIs compared to other types of FSWs, mainly due to their social status and engaging in sex work in an extremely 


\begin{tabular}{|c|c|c|c|c|c|c|c|}
\hline & Study & Events & Total & & & Proportion & $95 \%-\mathrm{Cl}$ \\
\hline & $1992-2009$ & & & & & & \\
\hline & Valle`s 2009 & 200 & 297 & & + & 0.67 & {$[0.62 ; 0.73]$} \\
\hline & Miyashita 2009 & 211 & 369 & & + & 0.57 & {$[0.52 ; 0.62]$} \\
\hline & del Amo 2009 & 169 & 549 & + & & 0.31 & {$[0.27 ; 0.35]$} \\
\hline & Sultana 2008 & 222 & 293 & & + & 0.76 & {$[0.70 ; 0.81]$} \\
\hline & Sarkar 2008 & 58 & 229 & + & & 0.25 & {$[0.20 ; 0.31]$} \\
\hline & Hernandez 2008 & 239 & 282 & & + & 0.85 & {$[0.80 ; 0.89]$} \\
\hline & Yun 2008 & 157 & 188 & & $\mp$ & 0.84 & {$[0.77 ; 0.89]$} \\
\hline & Gazi 2008 & 12 & 124 & $\mp$ & & 0.10 & {$[0.05 ; 0.16]$} \\
\hline & Didelot-Rousseau 2006 & 238 & 360 & & + & 0.66 & {$[0.61 ; 0.71]$} \\
\hline & Chandeying 2006 & 120 & 524 & + & & 0.23 & {$[0.19 ; 0.27]$} \\
\hline & De Marco 2006 & 28 & 64 & 1 & - & 0.44 & {$[0.31 ; 0.57]$} \\
\hline & del Amo 2005 & 283 & 734 & + & & 0.39 & {$[0.35 ; 0.42]$} \\
\hline & Canadas 2004 & 52 & 187 & 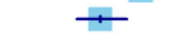 & & 0.28 & {$[0.22 ; 0.35]$} \\
\hline & Baay 2004 & 19 & 61 & $\longrightarrow$ & & 0.31 & {$[0.20 ; 0.44]$} \\
\hline & Mak 2004 & 72 & 99 & & $\hookrightarrow$ & 0.73 & {$[0.63 ; 0.81]$} \\
\hline & Tideman 2003 & 91 & 288 & + & & 0.32 & {$[0.26 ; 0.37]$} \\
\hline & Choi 2003 & 194 & 417 & + & & 0.47 & {$[0.42 ; 0.51]$} \\
\hline & Juarez-Figueroa 2001 & 242 & 495 & + & & 0.49 & {$[0.44 ; 0.53]$} \\
\hline & Chan 2001 & 27 & 187 & + & & 0.14 & {$[0.10 ; 0.20]$} \\
\hline & Kjaer 2000 & 59 & 182 & + & & 0.32 & {$[0.26 ; 0.40]$} \\
\hline & Ishi 2000 & 307 & 546 & & + & 0.56 & {$[0.52 ; 0.60]$} \\
\hline & Kreiss 1992 & 66 & 198 & 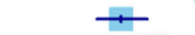 & & 0.33 & {$[0.27 ; 0.40]$} \\
\hline & Langley 1996 & 293 & 681 & + & & 0.43 & {$[0.39 ; 0.47]$} \\
\hline & Van Doornum 1993 & 21 & 121 & 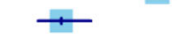 & & 0.17 & {$[0.11 ; 0.25]$} \\
\hline & $\begin{array}{l}\text { Overall } \\
p^{2}=97 \%, p<0.01\end{array}$ & 3380 & 7475 & 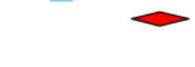 & & 0.44 & {$[0.36 ; 0.51]$} \\
\hline & $2010-2019$ & & & & & & \\
\hline & Velazquez-Hernandez 2019 & 12 & 217 & $\mp$ & & 0.06 & {$[0.03 ; 0.09]$} \\
\hline & Diop-Ndiaye 2019 & 348 & 436 & & $\mp$ & 0.80 & {$[0.76 ; 0.83]$} \\
\hline & Ferre 2019 & 140 & 310 & + & & 0.45 & {$[0.40 ; 0.51]$} \\
\hline & Shahesmaeili 2018 & 552 & 1318 & $\mp$ & & 0.42 & {$[0.39 ; 0.45]$} \\
\hline & Muñoz-Ramírez 2018 & 6 & 105 & $\mp$ & & 0.06 & {$[0.02 ; 0.12]$} \\
\hline & Hooi 2018 & 19 & 76 & 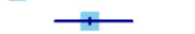 & & 0.25 & {$[0.16 ; 0.36]$} \\
\hline & Richards 2018 & 62 & 143 & $\longrightarrow$ & & 0.43 & {$[0.35 ; 0.52]$} \\
\hline & Bui 2018 & 94 & 200 & $\longrightarrow$ & & 0.47 & {$[0.40 ; 0.54]$} \\
\hline & Cameron 2018 & 97 & 330 & $\mp$ & & 0.29 & {$[0.25 ; 0.35]$} \\
\hline & Nasirian 2017 & 7 & 99 & $\mp$ & & 0.07 & {$[0.03 ; 0.14]$} \\
\hline & Marra 2017 & 238 & 304 & & + & 0.78 & {$[0.73 ; 0.83]$} \\
\hline & Vorsters 2016 & 556 & 1334 & $\mp$ & & 0.42 & {$[0.39 ; 0.44]$} \\
\hline & Menon 2016 & 357 & 616 & & $\mp$ & 0.58 & {$[0.54 ; 0.62]$} \\
\hline & Singh 2016 & 33 & 120 & 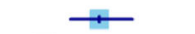 & & 0.28 & {$[0.20 ; 0.36]$} \\
\hline & Leaungwutiwong 2015 & 13 & 100 & $\mp$ & & 0.13 & {$[0.07 ; 0.21]$} \\
\hline & Jia 2015 & 191 & 309 & & $\rightarrow$ & 0.62 & {$[0.56 ; 0.67]$} \\
\hline & Gomih-Alakija 2014 & 103 & 349 & $\mp$ & & 0.30 & {$[0.25 ; 0.35]$} \\
\hline & Wang 2013 & 192 & 288 & & $\mp$ & 0.67 & {$[0.61 ; 0.72]$} \\
\hline & Patel 2013 & 195 & 296 & & $\mp$ & 0.66 & {$[0.60 ; 0.71]$} \\
\hline & Marek 2013 & 28 & 34 & & $\longrightarrow$ & 0.82 & {$[0.65 ; 0.93]$} \\
\hline & Hoang 2013 & 139 & 281 & 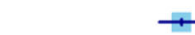 & - & 0.49 & {$[0.43 ; 0.55]$} \\
\hline & Ersan 2013 & 48 & 239 & + & & 0.20 & {$[0.15 ; 0.26]$} \\
\hline & Yin 2013 & 309 & 802 & + & & 0.39 & {$[0.35 ; 0.42]$} \\
\hline & Keten 2013 & 53 & 137 & 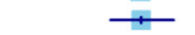 & & 0.39 & {$[0.30 ; 0.47]$} \\
\hline & Li 2012 & 315 & 810 & $\mp$ & & 0.39 & {$[0.36 ; 0.42]$} \\
\hline & Ghosh 2012 & 35 & 45 & & $\longrightarrow$ & 0.78 & {$[0.63 ; 0.89]$} \\
\hline & Couture 2012 & 90 & 220 & 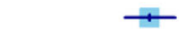 & & 0.41 & {$[0.34 ; 0.48]$} \\
\hline & Brown 2012 & 133 & 199 & & 7 & 0.67 & {$[0.60 ; 0.73]$} \\
\hline & Shikova 2011 & 46 & 106 & $\longrightarrow$ & & 0.43 & {$[0.34 ; 0.53]$} \\
\hline & Matsushita 2011 & 103 & 196 & & $\mp$ & 0.53 & {$[0.45 ; 0.60]$} \\
\hline & Znazen 2010 & 83 & 188 & 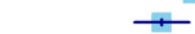 & & 0.44 & {$[0.37 ; 0.52]$} \\
\hline & Smith 2010 & 33 & 90 & 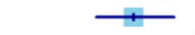 & & 0.37 & {$[0.27 ; 0.47]$} \\
\hline & Luchters 2010 & 429 & 776 & & $\mp$ & 0.55 & {$[0.52 ; 0.59]$} \\
\hline & Lockhart 2019 & 97 & 344 & $\mp$ & & 0.28 & {$[0.24 ; 0.33]$} \\
\hline & Adams 2019 & 26 & 100 & $\longrightarrow$ & & 0.26 & {$[0.18 ; 0.36]$} \\
\hline & Dal Pogetto 2011 & 46 & 102 & $\longrightarrow$ & & 0.45 & {$[0.35 ; 0.55]$} \\
\hline & Rhee 2010 & 939 & 2308 & $\mp$ & & 0.41 & {$[0.39 ; 0.43]$} \\
\hline & Overall & 6167 & 13927 & $<$ & & 0.42 & {$[0.37 ; 0.47]$} \\
\hline & $P^{2}=96 \%, p<0.01$ & & & $T$ & $\neg$ & & \\
\hline & & & & 0.2 & 0.6 & & \\
\hline
\end{tabular}


Table 2 Subgroup analysis of the prevalence of HPV infection in female sex workers

\begin{tabular}{|c|c|c|c|c|c|}
\hline Characteristics & Categories & No. of Studies & $\begin{array}{l}\text { Pooled prevalence } \\
\text { (\%) }(95 \% \mathrm{Cl})\end{array}$ & $\begin{array}{l}\text { Heterogeneity test } \\
\mathrm{I}^{2} \%, p \text {-value }\end{array}$ & $\begin{array}{l}\text { Differences between } \\
\text { subgroups; } x^{2} \text { test } \\
\text { ( } p \text {-value) }\end{array}$ \\
\hline Overall & & 61 & $42.6(38.5-46.7)$ & $96.9 \%, P<0.0001$ & \\
\hline \multirow[t]{4}{*}{ Diagnostic method } & PCR & 46 & $43.2(37.8-48.8)$ & $97.0 \%, P<0.01$ & $P=0.02 \dagger$ \\
\hline & Hybridization & 7 & $41.4(32.4-51.1)$ & $96.2 \%, P<0.01$ & \\
\hline & PCR-Hybridization & 3 & $40.9(37.7-44.2)$ & $58.4 \%, P=0.09$ & \\
\hline & TMA & 4 & $31.8(26.6-37.6)$ & $75.0 \%, P<0.01$ & \\
\hline \multirow[t]{4}{*}{ Sample type } & Cervical & 50 & $41.9(37.6-46.4)$ & $96.6 \%, P<0.01$ & $P=0.04 \dagger$ \\
\hline & Endocervical & 4 & $31.1(21.1-43.4)$ & $92.1 \%, P<0.01$ & \\
\hline & Vaginal & 3 & $68.4(37.7-88.5)$ & $99.2 \%, P<0.01$ & \\
\hline & Cervico-vaginal & 2 & $46.2(40.2-52.2)$ & $0 \%, P=0.65$ & \\
\hline \multirow[t]{4}{*}{ Diagnostic index } & L1 gene & 26 & $45.1(38.0-52.3)$ & $96.9 \%, P<0.01$ & $P<0.0001 \dagger$ \\
\hline & E6/E7 mRNA transcripts & 4 & $31.8(26.6-37.6)$ & $75.0 \%, P<0.01$ & \\
\hline & E6 gene & 1 & $75.7(70.5-80.3)$ & $N A, N A$ & \\
\hline & E6/E7 genes & 1 & $26.0(18.3-35.4)$ & $N A, N A$ & \\
\hline \multirow[t]{2}{*}{ Study year } & 1992-2009 & 24 & $43.6(36.1-51.4)$ & $97 \%, P<0.01$ & $P=0.71$ \\
\hline & 2010-2019 & 37 & $41.9(37.2-46.8)$ & $97 \%, P<0.01$ & \\
\hline
\end{tabular}

NA Not applicable, $P C R$ Polymerase chain reaction, TMA Transcription-mediated amplification;

† Statistically significant

unsafe workplace $[101,102]$. However, as a limitation, data regarding the sexual behaviors, sex work environments, or type of sex worker did not include in our meta-analysis.

Our results showed that HPV-16 and HPV-52 are the most commonly identified genotypes in FSWs. HPV-16 is considered as the most prominent type involved in the development of cervical cancer and other HPV-associated malignancies. HPV-52 is also an oncogenic HPV type, which is closely related phylogenetically to HPV-16. Previous studies have shown that HPV-52 is the sixth most frequently detected HPV high-risk type in CIN3 and invasive cervical cancer [103].

Similar to Asian countries, the prevalence of HPV positivity was significantly high among European FSWs. Despite high coverage HPV vaccination among females in Europe, our meta-analysis indicated that HPV infection is very common among FSWs in the Netherlands, Belgium, Bulgaria, Denmark, Hungary, and Spain, with a prevalence of HPV infection between 30 and $80 \%$. Our explanation is that vaccination does not protect against HPV types other than $6,11,16$, and 18 . For instance, the majority of FSWs in the Netherlands were infected with types different than what was covered by the current vaccines [51]. To overcome this problem, we recommend the use of a nine-valent vaccine (9vHPV) instead of the bivalent and quadrivalent vaccines. The
9vHPV vaccine contains type $6,11,16,18,31,33,45$, 52 , and 58 which was approved by the FDA in December 2014, and by the European Medicines Agency (EMA) in June 2015 [104].

Based on the results of the study, we found that the variations in the prevalence of HPV infection in FSWs across the studies could not be explained by the difference in detection methods. This is due to that the detection rates were similar for HPV using PCR, hybridization, and PCR-hybridization, which were applied in 56 (93.3\%) studies. However, sample type may be one of the factors leading to differences in prevalence rates. To confirm this finding, our meta-analysis demonstrated that the detection rate of HPV using vaginal samples was significantly higher than cervical, endocervical, and cervico-vaginal samples. We concluded that the vaginal sample is more sensitive for detecting HPV and has a higher level of HPV DNA than the other genital specimens in FSWs. Furthermore, vaginal sampling is a less invasive method and is easily available for all women at the time of a regular HPV test. Owing to the high prevalence of HPV in vaginal samples, vaginal douching with disinfectants after sex with clients seemed to be an effective practice in the reduction of HPV transmission.

In some countries, such as Thailand, Singapore, and Iran, the HPV prevalence is unexpectedly low, and we believe that this is due to several reasons, like limited 


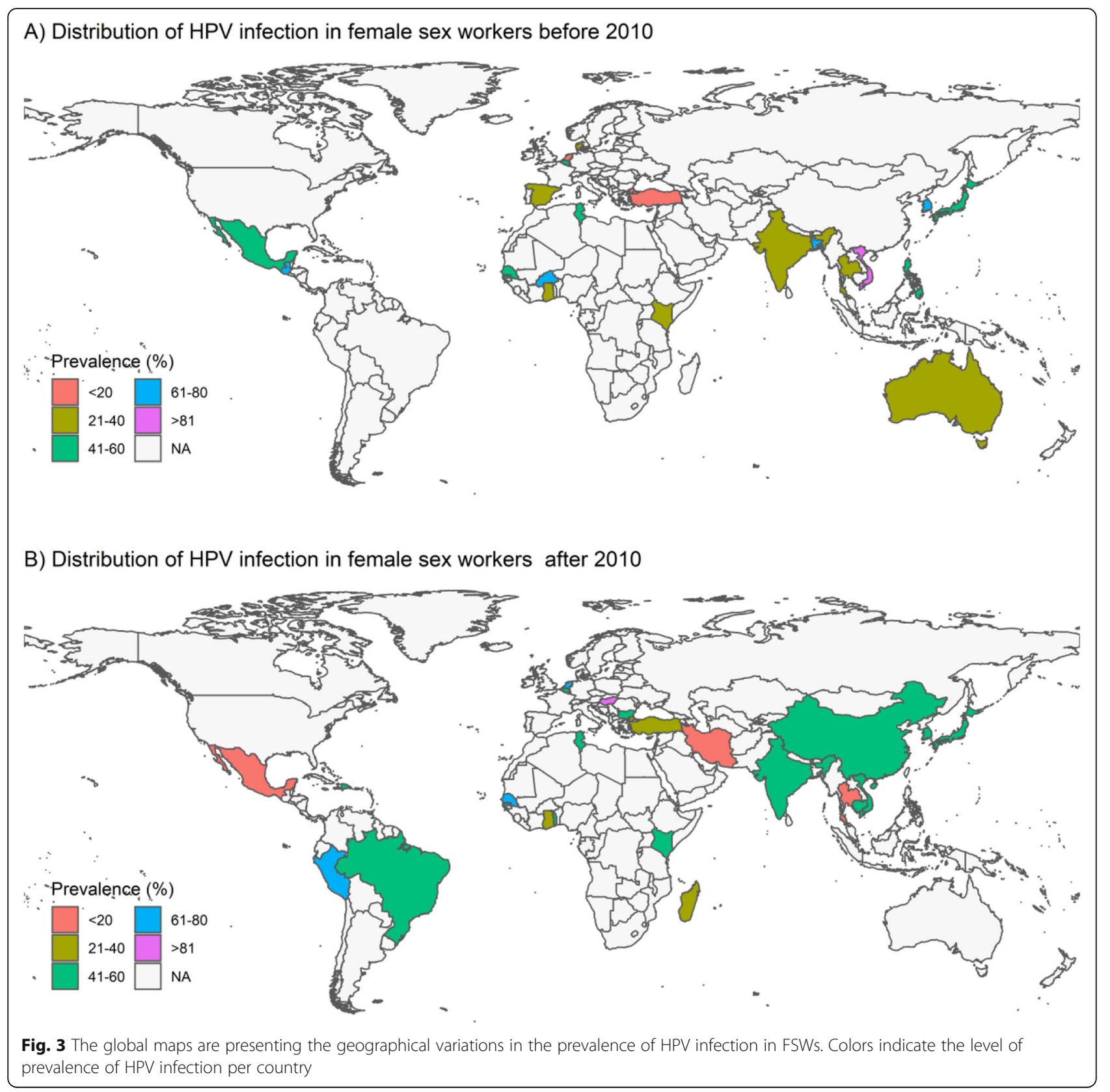

HPV screening practices, low socioeconomic status, the illegality of sex work, severely limited support systems, unsafe workplaces, fear of stigmatization, and lack of education or skills. Thus, it is so likely that the obtained results in our meta-analysis may not be a precise estimate of the HPV prevalence in these regions.

The present study has some limitations that need to be considered during the interpretation of our results. First, a significant part of the studies investigating the HPV prevalence among FSWs did not perform analysis of HPV genotype distribution, and thus we could not include their results in our meta-analysis of the genotype distribution of HPV. Second, despite the subgroup analyses, significant heterogeneity still existed, suggesting that it arises from other sources that we could not characterize. Finally, there were no published data on the prevalence of HPV infection among FSWs in so many countries such as the United States, Canada, Russia, France, Germany, Italy, the United Kingdom, Nigeria, South Africa, Cameroon, and the Arabian Peninsula.

The HPV vaccination is of public health importance, and since 2009, the World Health Organization (WHO) 


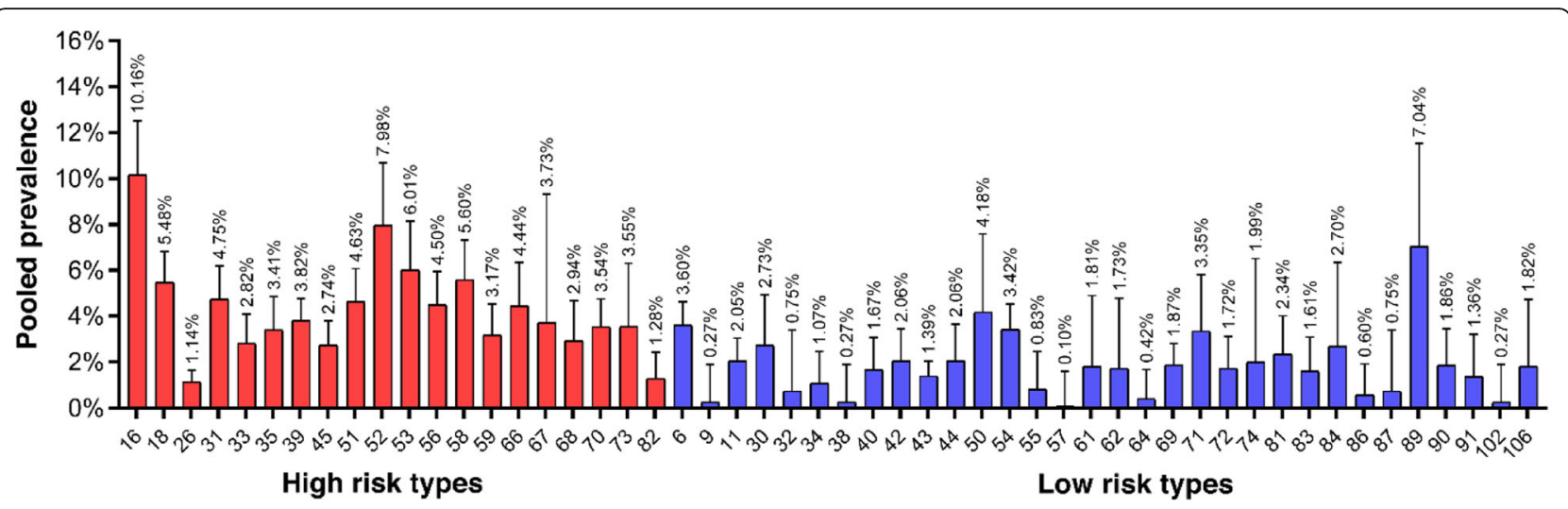

Fig. 4 Prevalence and genotype distribution of genital HPV (high-risk and low-risk) among FSWs

has recommended the HPV vaccination as a preventive measure against cervical cancer with a primary target population of girls aged 9 to 14 years. As of mid-2019, however, HPV vaccines have been introduced only in 93 countries [105], and many countries still have not implemented national HPV vaccination programs. Governments should consider that HPV vaccination is a cost-effective intervention for the prevention of cervical cancer. Low socioeconomic conditions such as poverty, poor income, and low education levels are often regarded as the main reasons for the involvement of women in sex work. FSWs are a marginalized and stigmatized population across the world and are highly vulnerable to various forms of violence. Previous studies have indicated that the risk of acquiring STIs among FSWs who have experienced violence is nearly three times greater compared to FSWs who have not experienced violence [106]. Criminalization of sex work is associated with more social stigma and increased vulnerability of FSWs to violence [107]. Comprehensive efforts should be directed and prioritized toward reducing violence against this vulnerable population as the vital preventive measures of STIs such as HPV infection.

\section{Conclusions}

In summary, FSWs are a neglected population around the world with a high prevalence of HPV infection, deserving greater attention. Our findings showed that high-risk HPV types are common among FSWs. Persistent infection with high-risk HPV types is the strongest risk factor for the development of cervical intraepithelial neoplasia and cervical or vaginal cancers. Besides, they can transmit their infection to their male clients, which leads to a high HPV prevalence and incidence of HPV- associated malignancies among the general population. Therefore, public health interventions, such as the implementation of national HPV vaccination strategies (particularly by 9vHPV vaccine), regular screening of FSWs for HPV, and encouraging safersex strategies like condom use are critical.

\section{Supplementary information}

Supplementary information accompanies this paper at https://doi.org/10. 1186/s12889-020-09570-z.

\section{Additional file 1}

\section{Abbreviations}

FSWs: Female sex workers; HPV: Human papillomavirus; Cl: Confidence interval; STIs: Sexually transmitted Infections; TMA: Transcription-mediated amplification; CIN: Cervical intraepithelial neoplasia; EMA: European Medicines Agency; 9vHPV: Nine-valent HPV vaccine; MSM: Men who have sex with men; ASCUS: Atypical squamous cells of undetermined significance

\section{Acknowledgments}

Not applicable.

\section{Authors' contributions}

Ahmad Tavakoli and Mohammad Farahmand designed the study.

Mohammad Farahmand performed statistical analysis. Ahmad Tavakoli wrote, reviewed, and edited the manuscript. Seyed Hamidreza Monavari and Seyed Jalal Kiani performed data interpretation. Mohsen Moghoofei, Ahmad Tavakoli and Mohammad Farahmand performed search strategy and acquisition of data. Mohammad Farahmand, Ahmad Tavakoli, Abolfazl Dorost, and Saeedeh Abbasi made revisions and replied to comments. The authors read and approved the final draft.

Funding

This study was not financially supported by any individual, agency, or institution.

Availability of data and materials

All data generated or analyzed during this study are included in this article.

Ethics approval and consent to participate

Not applicable.

Consent for publication

Not applicable. 


\section{Competing interests}

The authors have no conflict of interest.

\begin{abstract}
Author details
'Department of Virology, School of Public Health, Tehran University of Medical Sciences, Tehran, Iran. ${ }^{2}$ Department of Microbiology, Faculty of Medicine, Kermanshah University of Medical Sciences, Kermanshah, Iran ${ }^{3}$ Department of Health Economics and Management, School of Public Health, Tehran University of Medical Sciences, Tehran, Iran. ${ }^{4}$ Department of Medical Virology, Faculty of Medicine, Iran University of Medical Sciences, Tehran, Iran. ${ }^{5}$ Research Center of Pediatric Infectious Diseases, Institute of Immunology and Infectious Diseases, Iran University of Medical Sciences, Tehran, Iran.
\end{abstract}

Received: 7 March 2020 Accepted: 20 September 2020 Published online: 25 September 2020

\section{References}

1. Bihl MP, Tornillo L, Kind AB, Obermann E, Noppen C, Chaffard R, et al. Human papillomavirus (HPV) detection in cytologic specimens: similarities and differences of available methodology. Appl Immunohistochem Mol Morphol. 2017;25(3):184.

2. Ozaydin-Yavuz G, Bilgili SG, Guducuoglu H, Yavuz IH, Elibuyuk-Aksac S, Karadag AS. Determinants of high-risk human papillomavirus infection in anogenital warts. Postepy Dermatol Alergol. 2019;36(1):76-81.

3. Min K-J, Kwon S-H, Kim K, Kim S, Kim HJ, Seong SJ, et al. Clinical guideline for 9-valent HPV vaccine: Korean Society of Gynecologic Oncology Guideline. Gynecol Oncol. 2018;30(2):1-10.

4. Schmitt M, Depuydt C, Benoy I, Bogers J, Antoine J, Arbyn M, et al. Prevalence and viral load of 51 genital human papillomavirus types and three subtypes. Int J Cancer. 2013;132(10):2395-403.

5. Kim KS, Park S, Ko K-N, Yi S, Cho YJ. Current status of human papillomavirus vaccines. Clin Exp Vaccine Res. 2014:3(2):168-75.

6. Pils S, Joura E. From the monovalent to the nine-valent HPV vaccine. Clin Microbiol Infect. 2015;21(9):827-33.

7. Bucchi D, Stracci F, Buonora N, Masanotti G. Human papillomavirus and gastrointestinal cancer: a review. World J Gastroenterol. 2016;22(33):7415-30.

8. Marra E, Lin C, Clifford GM. Type-specific anal human papillomavirus prevalence among men, according to sexual preference and HIV status: a systematic literature review and meta-analysis. J Infect Dis. 2019;219(4):5908.

9. Sabeena S, Bhat PV, Kamath V, Bhat SK, Nair S. Community-based prevalence of genital human papilloma virus (HPV) infection: a systematic review and meta-analysis. Asian Pac J Cancer Prev. 2017;18(1):145-54.

10. Manikandan S, Behera S, Naidu NM, Angamuthu V, Mohammed OFB, Debata A. Knowledge and awareness toward cervical cancer screening and prevention among the professional college female students. J Pharm Bioallied Sci. 2019;11(Suppl 2):S314-20.

11. Kaliterna V, Barisic Z. Genital human papillomavirus infections. Front Biosci (Landmark Ed). 2018;23:1587-611.

12. Jain A, Ganesh B, Bobdey SC, Sathwara JA, Saoba S. Sociodemographic and clinical profile of cervical cancer patients visiting in a tertiary care hospital in India. Indian J Med Paediatr Oncol. 2017;38(3):291-5

13. Liu Z-C, Liu W-D, Liu Y-H, Ye X-H, Chen S-D. Multiple sexual partners as a potential independent risk factor for cervical cancer: a meta-analysis of epidemiological studies. Asian Pac J Cancer Prev. 2015;16(9):3893-900.

14. Adams AR, Nortey PA, Dortey BA, Asmah RH, Wiredu EK. Cervical human papillomavirus prevalence, genotypes, and associated risk factors among female sex Workers in Greater Accra, Ghana. J Oncol. 2019;201:1-7.

15. Bellhouse C, Crebbin S, Fairley CK, Bilardi JE. The impact of sex work on women's personal romantic relationships and the mental separation of their work and personal lives: a mixed-methods study. PLoS One. 2015;10(10):120.

16. Sawicki DA, Meffert BN, Read K, Heinz AJ. Culturally competent health care for sex workers: an examination of myths that stigmatize sex work and hinder access to care. Sex Relatsh Ther. 2019;34(3):355-71.

17. Mamulwar M, Godbole S, Bembalkar S, Kamble P, Dulhani N, Yadav R, et al. Differing HIV vulnerability among female sex workers in a high HIV burden Indian state. PLoS One. 2018;13(2):e0192130.
18. Guida J, Hu L, Liu H. Sexual behavior with noncommercial partners: a concurrent partnership study among middle-aged female sex Workers in China. J Sex Res. 2019;56(4-5):670-80.

19. Strathdee SA, West BS, Reed E, Moazan B, Azim T, Dolan K. Substance use and HIV among female sex workers and female prisoners: risk environments and implications for prevention, treatment, and policies. J Acquir Immune Defic Syndr. 2015;69 Suppl 2(01):S110-7.

20. Atif $M$, Khalil R, Bilal B. Prevalence of condom use and associated factors among female sex workers in Karachi, Pakistan. Int J Cur Res Rev. 2015;7(23): 40-6.

21. Hemalatha R, Kumar RH, Venkaiah K, Srinivasan K, Brahmam G. Prevalence of \& knowledge, attitude \& practices towards HIV \& sexually transmitted infections (STIs) among female sex workers (FSWs) in Andhra Pradesh. Indian J Med Res. 2011;134(4):470

22. Adithyan G, Rakshase B, Ekstrom AM. A study on HIV knowledge and preventive behavioral practices among FSWS in Mumbai. J AIDS HIV Res. 2017:9(1):1-7.

23. Nyagero J, Wangila S, Kutai V, Olango S. Behaviour change and associated factors among female sex workers in Kenya. Pan Afr Med J. 2012:13(Suppl 1):1-6.

24. Ersan G, Kose S, Senger SS, Gunes H, Sehirali S, Gurbuz I. The prevalence and risk factors of human papillomavirus in female sex workers. Eur J Med. 2013;45(1):16-20.

25. Stratton $\mathrm{KL}$, Culkin DJ. A contemporary review of HPV and penile cancer. Oncology. 2016:30(3):245-9.

26. Vallès $X$, Murga GB, Hernández $G$, Sabidó M, Chuy A, Lloveras B, et al. High prevalence of human papillomavirus infection in the female population of Guatemala. Int J Cancer. 2009:125(5):1161-7.

27. Leung KM, Yeoh GP, Cheung HN, Fong FY, Chan KW. Prevalence of abnormal Papanicolaou smears in female sex workers in Hong Kong. Hong Kong Med J. 2013;19(3):203-6.

28. Jia $H$, Wang $X$, Long $Z$, Li L. Human papillomavirus infection and cervica dysplasia in female sex workers in Northeast China: an observational study. BMC Public Health. 2015:15(1):1-6.

29. Hooi DJ, Quint WG, Lissenberg-Witte BI, Kenter G, Pinedo HM, de Koning MN, et al. Human papillomavirus (HPV) types prevalence in cervical samples of female sex-workers on Curaçao. Prev Med Rep. 2018;11:120-4.

30. Soohoo M, Blas M, Byraiah G, Carcamo C, Brown B. Cervical HPV infection in female sex workers: a global perspective. Open AIDS J. 2013;7:58-66.

31. Peng R-R, Li H-M, Chang H, Li J-H, Wang AL, Chen X-S. Prevalence and genotype distribution of cervical human papillomavirus infection among female sex workers in Asia: a systematic literature review and meta-analysis. Sex Health. 2012:9(2):113-9.

32. Moher D, Liberati A, Tetzlaff J, Altman DG, Group P. Preferred reporting items for systematic reviews and meta-analyses: the PRISMA statement. PLoS Med. 2009;6(7):1-6

33. Moosazadeh M, Nekoei-moghadam M, Emrani Z, Amiresmaili M. Prevalence of unwanted pregnancy in Iran: a systematic review and meta-analysis. Int Health Plann Manage. 2014;29(3):e277-e90.

34. Eslamipour F, Afshari Z, Najimi A. Prevalence of orthodontic treatment need in permanent dentition of Iranian population: a systematic review and meta-analysis of observational studies. Dent Res J. 2018;15(1):1-10.

35. DerSimonian R, Laird N. Meta-analysis in clinical trials. Control Clin Trials. 1986;7(3):177-88.

36. Analysing data and undertaking meta-analyses. Cochrane Handbook for Systematic Reviews of Interventions. 2019. p. 241-284.

37. Newcombe RG. Two-sided confidence intervals for the single proportion: comparison of seven methods. Stat Med. 1998;17(8):857-72.

38. Higgins JP, Thompson SG, Deeks JJ, Altman DG. Measuring inconsistency in meta-analyses. Bmj. 2003;327(7414):557-60.

39. Jackson D. Confidence intervals for the between-study variance in random effects meta-analysis using generalised Cochran heterogeneity statistics. Res Synth Methods. 2013;4(3):220-9.

40. Schwarzer G. Meta: an R package for meta-analysis. R news. 2007:7(3):40-5

41. Velazquez-Hernandez N, Sanchez-Anguiano LF, Guerra-Infante FM, AguilarDuran M, Perez-Alamos AR, Estrada-Martinez S, et al. Human papillomavirus infection in female sex workers: a case control study. J Clin Med Res. 2019; 11(3):196-201.

42. Diop-Ndiaye H, Beiter K, Gheit T, Ndoye AS, Dramé A, McKay-Chopin S, et al. Human papillomavirus infection in Senegalese female sex workers. Papillomavirus Res. 2019;7:97-101. 
43. Ferré VM, Gbeasor-Komlanvi FA, Collin G, Dagnra AC, Le Hingrat Q, Jaquet $A$, et al. Prevalence of human papillomavirus, human immunodeficiency virus, and other sexually transmitted infections among men who have sex with men in Togo: a National Cross-sectional Survey. Clin Infect Dis. 2019; 69(6):1019-26

44. Lockhart A, Senkomago V, Ting J, Chitwa M, Kimani J, Gakure H, et al. Prevalence and risk factors of Trichomonas vaginalis among female sexual Workers in Nairobi, Kenya. Sex Transm Dis. 2019;46(7):458-64.

45. Shahesmaeili A, Karamouzian M, Shokoohi M, Kamali K, Fahimfar N, Nadj SA, et al. Symptom-based versus laboratory-based diagnosis of five sexually transmitted infections in female sex workers in Iran. AIDS Behav. 2018;22(1): 19-25.

46. Munoz-Ramirez A, Lopez-Monteon A, Ramos-Ligonio A, Mendez-Bolaina E, Guapillo-Vargas MR. Prevalence of Trichomonas vaginalis and human papillomavirus in female sex workers in Central Veracruz, Mexico. Rev Argent Microbiol. 2018;50(4):351-8.

47. Richards SD, Stonbraker S, Halpern M, Amesty S. Cervical cancer screening among transactional female sex workers in the Dominican Republic. Int J STD AIDS. 2018;29(12):1204-14.

48. Bui TC, Scheurer ME, Pham VTT, Tran LTH, Hor LB, Vidrine DJ, et al. Intravaginal practices and genital human papillomavirus infection among female sex workers in Cambodia. J Med Virol. 2018;90(11):1765-74.

49. Cameron JE, Rositch AF, Vielot NA, Mugo NR, Kwatampora JK, Waweru W, et al. Epstein-Barr virus, high-risk human papillomavirus and abnormal cervical cytology in a prospective cohort of African female sex workers. Sex Transm Dis. 2018;45(10):1-17.

50. Nasirian M, Kianersi S, Hoseini SG, Kassaian N, Yaran M, Shoaei P, et al. Prevalence of sexually transmitted infections and their risk factors among female sex workers in Isfahan, Iran: a cross-sectional study. J Int Assoc Provid AIDS Care. 2017;16(6):608-14.

51. Marra E, Kroone N, Freriks E, van Dam C, Alberts CJ, Hogewoning A, et al. Vaginal and anal human papillomavirus infection and seropositivity among female sex workers in Amsterdam, the Netherlands: prevalence, concordance and risk factors. J Inf Secur. 2018;76(4):393-405.

52. Vorsters A, Cornelissen T, Leuridan E, Bogers J, Broeck DV, Benoy I, et al. Prevalence of high-risk human papillomavirus and abnormal pap smears in female sex workers compared to the general population in Antwerp, Belgium. BMC Public Health. 2016;16(1):1-8

53. Menon S, Broeck DV, Rossi R, Ogbe E, Harmon S, Mabeya H. Associations between vaginal infections and potential high-risk and high-risk human papillomavirus genotypes in female sex workers in western Kenya. Clin Ther. 2016:38(12):2567-77.

54. Singh M, Kaur M, Gupta N, Kumar A, Goyal K, Sharma A, et al. Prevalence of high-risk human papilloma virus types and cervical smear abnormalities in female sex workers in Chandigarh, India. Indian J Med Microbiol. 2016;34(3): 328-34

55. Leaungwutiwong $P$, Bamrungsak $B$, Jittmittraphap $A$, Maneekan $P$, Kosoltanapiwat N, Kalambaheti T, et al. Molecular genotyping of HPV L1 gene in low-risk and high-risk populations in Bangkok. Sex Transm Dis. 2015;42(4):1-20.

56. Gomih-Alakija A, Ting J, Mugo N, Kwatampora J, Getman D, Chitwa M, et al. Clinical characteristics associated with mycoplasma genitalium among female sex workers in Nairobi, Kenya. J Clin Microbiol. 2014;52(10):3660-6.

57. Aho J, Koushik A, Coutlée F, Diakité SL, Rashed S. Prevalence of HIV, human papillomavirus type 16 and herpes simplex virus type 2 among female sex workers in Guinea and associated factors. Int J STD AIDS. 2014;25(4):280-8.

58. Wang X, Gu D, Lou B, Xu B, Qian F, Chen Y. Hospital-based prevalence of high-risk cervical HPV types infecting the general population and female sex workers in Huzhou, China. Int J Gynaecol Obstet. 2013;120(1):37-41.

59. Patel S, Mugo N, Cohen C, Ting J, Nguti R, Kwatampora J, et al. Multiple human papillomavirus infections and HIV seropositivity as risk factors for abnormal cervical cytology among female sex workers in Nairobi. Int J STD AIDS. 2013;24(3):221-5

60. Marek E, Dergez T, D'cruz G, Bózsa S, Cseh A, Szilárd I, et al. Human papillomavirus infections among $\mathrm{H}$ ungarian female sex workers. Eur J Cancer Care. 2014;23(1):65-75.

61. Hoang HTT, Ishizaki A, Nguyen CH, Tran VT, Matsushita K, Saikawa K, et al. Infection with high-risk HPV types among female sex workers in northern Vietnam. J Med Virol. 2013;85(2):288-94.

62. Yin Y-P, Li H-M, Xiang Z, Liang G-J, Shi M-Q, Zhou Y-J, et al. Association of sexually transmitted infections with high-risk human papillomavirus types: a survey with 802 female sex workers in China. Sex Transm Dis. 2013;40(6): 493-5.

63. Keten A, Keten D, ODABAŞI AB, Tezel GG, Güler G, TÜMER AR. Screening for and genotyping of human papilloma virus in prostitutes. Turk Klin Tip Bilim. 2013;33(3):601-6.

64. Li HM, Liang GJ, Yin YP, Wang QQ, Zheng ZJ, Zhou JJ, et al. Prevalence and genotype distribution of human papillomavirus infection among female sex workers in Guangxi, China: implications for interventions. J Med Virol. 2012; 84(5):798-803.

65. Ghosh I, Ghosh P, Bharti AC, Mandal R, Biswas J, Basu P. Prevalence of human papillomavirus and co-existent sexually transmitted infections among female sex workers, men having sex with men and injectable drug abusers from eastern India. Asian Pac J Cancer Prev. 2012;13(3):799-802.

66. Couture M-C, Page K, Stein ES, Sansothy N, Sichan K, Kaldor J, et al. Cervical human papillomavirus infection among young women engaged in sex work in Phnom Penh, Cambodia: prevalence, genotypes, risk factors and association with HIV infection. BMC Infect Dis. 2012;12(1):1-11.

67. Brown B, Blas M, Cabral A, Byraiah G, Guerra-Giraldez C, Sarabia-Vega V, et al Human papillomavirus prevalence, cervical abnormalities and risk factors among female sex workers in Lima, Peru. Int J STD AIDS. 2012;23(4):242-7.

68. Shikova E, Todorova I, Ganchev G, Kouseva-Dragneva V, Kalascheva-Zaimova $P$. Prevalence of human papillomavirus infection among female sex workers in Bulgaria. Int J STD AIDS. 2011;22(5):278-80.

69. Matsushita K, Sasagawa T, Miyashita M, Ishizaki A, Morishita A, Hosaka N, et al. Oral and cervical human papillomavirus infection among female sex workers in Japan. Jpn J Infect Dis. 2011;64(1):34-9.

70. Pogetto B-D, Rodrigues M, Silva MG. Parada CMGdL. Prevalence of sexually transmitted diseases in female sex workers in a city in the interior of São Paulo, Brazil. Rev Lat Am Enfermagem. 2011;19(3):493-9.

71. Znazen A, Frikha-Gargouri O, Berrajah L, Bellalouna S, Hakim H, Gueddana N et al. Sexually transmitted infections among female sex workers in Tunisia: high prevalence of chlamydia trachomatis. Sex Transm Infect. 2010;86(7): 500-5.

72. Smith JS, Van Damme K, Randrianjafisamindrakotroka N, Ting J, Rabozakandraina T, Randrianasolo BS, et al. Human papillomavirus and cervical neoplasia among female sex workers in Madagascar. Int J Gynecol Cancer. 2010;20(9):1593-6.

73. Luchters SM, Broeck DV, Chersich MF, Nel A, Delva W, Mandaliya K, et al. Association of HIV infection with distribution and viral load of HPV types in Kenya: a survey with 820 female sex workers. BMC Infect Dis. 2010;10(1):110.

74. Rhee JE, Shin MY, Kim CM, Kee HY, Chung JK, Min S-K, et al. Prevalence of human papillomavirus infection and genotype distribution among high-risk Korean women for prospecting the strategy of vaccine development. Virol J. 2010;7(1):1-4

75. Miyashita M, Agdamag DM, Sasagawa T, Matsushita K, Salud LM, Salud CO, et al. High-risk HPV types in lesions of the uterine cervix of female commercial sex workers in the Philippines. J Med Virol. 2009;81(3):545-51.

76. del Amo J, González C, Belda J, Fernández E, Martínez R, Gómez I, et al. Prevalence and risk factors of high-risk human papillomavirus in female sex workers in Spain: differences by geographical origin. J Womens Health. 2009;18(12):2057-64

77. Sultana T, Huq M, Alam A, Mitra DK, Gomes DJ. Prevalence and genotyping of human papillomavirus (HPV) in female with high-risk behaviour in Dhaka, Bangladesh. Bangladesh J Microbiol. 2008;25(1):65-8.

78. Sarkar K, Bhattacharya S, Bhattacharyya S, Chatterjee S, Mallick AH, Chakraborti S, et al. Oncogenic human papilloma virus and cervical precancerous lesions in brothel-based sex workers in India. J Infect Public Health. 2008;1(2):121-8.

79. Hernandez BY, Nguyen TV. Cervical human papillomavirus infection among female sex workers in southern Vietnam. Infect Agent Cancer. 2008;3(1):1-9.

80. Yun H, Park J, Choi I, Kee M, Choi B, Kim S. Prevalence of human papillomavirus and herpes simplex virus type 2 infection in Korean commercial sex workers. J Microbiol Biotechnol. 2008;18(2):350-4.

81. Gazi H, Surucuoglu S, Yolasigmaz G, Sen M, Akcali S, Dinc G, et al. Prevalence of chlamydia trachomatis/Neisseria gonorrhoeae and human papilloma virus among women-at risk in the Aegian region of Turkey, and their knowledge about HIV/AIDS. West Indian Med J. 2008;57(4):398-402.

82. Didelot-Rousseau M-N, Nagot N, Costes-Martineau V, Valles X, Ouedraogo A, Konate I, et al. Human papillomavirus genotype distribution and cervical 
squamous intraepithelial lesions among high-risk women with and without HIV-1 infection in Burkina Faso. Br J Cancer. 2006;95(3):355-62.

83. Chandeying V, Garland SM, Tabrizi SN. Prevalence and typing of human papilloma virus (HPV) among female sex workers and outpatient women in southern Thailand. Sex Health. 2006;3(1):11-4.

84. De Marco F, Houissa-Kchouk F, Khelifa R, Marcante ML. High-risk HPV types in Tunisia. A pilot study reveals an unexpectedly high prevalence of types 58 and 82 and lack of HPV 18 among female prostitutes. J Med Virol. 2006; 78(7):950-3.

85. del Amo J, González C, Losana J, Clavo P, Munoz L, Ballesteros J, et al. Influence of age and geographical origin in the prevalence of high risk human papillomavirus in migrant female sex workers in Spain. Sex Transm Infect. 2005;81(1):79-84.

86. Cañadas MP, Bosch FX, Junquera ML, Ejarque M, Font R, Ordoñez E, et al. Concordance of prevalence of human papillomavirus DNA in anogenital and oral infections in a high-risk population. J Clin Microbiol. 2004;42(3): 1330-2.

87. Baay M, Verhoeven V, Wouters K, Lardon F, Van Damme P, Avonts D, et al. The prevalence of the human papillomavirus in cervix and vagina in lowrisk and high-risk populations. Scand J Infect Dis. 2004;36(6-7):456-9.

88. Mak R, Van Renterghem L, Cuvelier C. Cervical smears and human papillomavirus typing in sex workers. Sex Transm Infect. 2004;80(2):118-20.

89. Tideman R, Thompson C, Rose B, Gilmour S, Marks C, Van Beek I, et al. Cervical human papillomavirus infections in commercial sex workers-risk factors and behaviours. Int J STD AIDS. 2003;14(12):840-7.

90. Choi BS, Kim O, Park MS, Kim KS, Jeong JK, Lee JS. Genital human papillomavirus genotyping by HPV oligonucleotide microarray in Korean commercial sex workers. J Med Virol. 2003;71(3):440-5.

91. Juarez-Figueroa LA, Wheeler CM, Uribe-Salas FJ, Conde-Glez CJ, ZamilpaMejia LG, Garcia-Cisneros S, et al. Human papillomavirus: a highly prevalent sexually transmitted disease agent among female sex workers from Mexico City. Sex Transm Dis. 2001;28(3):125-30.

92. Chan R, Khoo L, Ho T, Koh CF, Lee I, Yam K, et al. A comparative study of cervical cytology, colposcopy and PCR for HPV in female sex workers in Singapore. Int J STD AIDS. 2001;12(3):159-63.

93. Kjaer SK, Svare El, Worm AM, Walboomers JM, Meijer CJ, Van den Brule AJ. Human papillomavirus infection in Danish female sex workers: decreasing prevalence with age despite continuously high sexual activity. Sex Transm Dis. 2000;27(8):438-45.

94. Ishi K, Suzuki F, Saito A, Kubota T. Prevalence of human papillomavirus infection and its correlation with cervical lesions in commercial-sex Workers in Japan. J Obstet Gynaecol Res. 2000;26(4):253-7.

95. Langley CL, Benga-De E, Critchlow CW, Ndoye I, Mbengue-Ly MD, Kuypers J, et al. HIV-1, HIV-2, human papillomavirus infection and cervical neoplasia in high-risk African women. Aids. 1996;10(4):413-8.

96. Van Doornum G, Van den Hoek J, Van Ameijden E, Van Haastrecht H, Roos MTL, Henquet C, et al. Cervical HPV infection among HIV-infected prostitutes addicted to hard drugs. J Med Virol. 1993;41(3):185-90.

97. Kreiss JK, Kiviat NB, Plummer FA, Roberts PL, Waiyaki P, Ngugi E, et al. Human immunodeficiency virus, human papillomavirus, and cervical intraepithelial neoplasia in Nairobi prostitutes. Sex Transm Dis. 1992;19(1):54.

98. Kaur P, Aggarwal A, Nagpal M, Oberoi L, Sharma S. Prevalence and clinical utility of human papilloma virus genotyping in patients with cervical lesions. J Obstet Gynaecol India. 2014;64(4):279-83.

99. Lépine A, Treibich C, Ndour CT, Gueye K, Vickerman P. HIV infection risk and condom use among sex workers in Senegal: evidence from the list experiment method. Health Policy Plan. 2020;35(4):408-15.

100. Sirotin N, Strathdee SA, Lozada R, Abramovitz D, Semple SJ, Bucardo J, et al. Effects of government registration on unprotected sex amongst female sex workers in Tijuana; Mexico. Int J Drug Policy. 2010;21(6):466-70.

101. Allen ST, Footer KH, Galai N, Park JN, Silberzahn B, Sherman SG. Implementing targeted sampling: lessons learned from recruiting female sex workers in Baltimore, MD. J Urban Health. 2019;96(3):442-51.

102. Goldenberg SM, Rangel G, Vera A, Patterson TL, Abramovitz D, Silverman JG, et al. Exploring the impact of underage sex work among female sex workers in two Mexico-US border cities. AIDS Behav. 2012;16(4):969-81.

103. Formentin A, Archambault J, Koushik A, Richardson H, Brassard P, Franco EL, et al. Human papillomavirus type 52 polymorphism and high-grade lesions of the uterine cervix. Int J Cancer. 2013;132(8):1821-30.
104. Mennini FS, Bonanni P, Bianic F, de Waure C, Baio G, Plazzotta G, et al. Costeffectiveness analysis of the nine-valent HPV vaccine in Italy. Cost Eff Resour Alloc. 2017;15(1):1-14.

105. Anwari P, Debellut F, Vodicka E, Clark A, Farewar F, Zhwak ZA, et al. Potential health impact and cost-effectiveness of bivalent human papillomavirus (HPV) vaccination in Afghanistan. Vaccine. 2020;38(6):135262.

106. Prakash R, Manthri S, Tayyaba S, Joy A, Raj SS, Singh D, et al. Effect of physical violence on sexually transmitted infections and treatment seeking behaviour among female sex workers in Thane District, Maharashtra, India. PLoS One. 2016;11(3):1-19.

107. Ma H, Loke AY. A qualitative study into female sex workers' experience of stigma in the health care setting in Hong Kong. Int J Equity Health. 2019; 18(1):1-14.

\section{Publisher's Note}

Springer Nature remains neutral with regard to jurisdictional claims in published maps and institutional affiliations.
Ready to submit your research? Choose BMC and benefit from:

- fast, convenient online submission

- thorough peer review by experienced researchers in your field

- rapid publication on acceptance

- support for research data, including large and complex data types

- gold Open Access which fosters wider collaboration and increased citations

- maximum visibility for your research: over $100 \mathrm{M}$ website views per year

At $\mathrm{BMC}$, research is always in progress.

Learn more biomedcentral.com/submissions 